\title{
Imagens, palavras, feridas: diálogos entre literatura e fotografia
}

\section{Images, words, wounds: dialogues between literature and photography}

\author{
Janaína Buchweitz e Silva* \\ janaesilva@yahoo.com.br \\ Universidade Federal de Pelotas
}

RESUMO: O artigo problematiza as relações entre literatura e fotografia partindo do romance O corpo interminável, narrativa em que o tema da fotografia encontra espaço predominante. Para a leitura teórica foram selecionados pesquisadores do campo da fotografia, tais como Benjamin (1996), Barthes (1984), Cartier-Bresson (2015), Sontag (2004), Bazin (1991) e Machado (2015). Buscou-se, nos pontos principais desenvolvidos pelos autores, a aplicabilidade das teorias para a leitura do texto literário, propiciando um discurso interartístico que potencializa novos elos entre literatura e fotografia.

PALAVRAS-CHAVE: literatura. fotografia. diálogos literários.

ABSTRACT: The article discusses the relationship between literature and photography based on the novel O corpo interminável, a narrative in which the theme of photography finds predominance space. For theoretical reading, theorists from the field of photography were selected, such as Benjamin (1996), Barthes (1984), CartierBresson (2015), Sontag (2004), Bazin (1991) and Machado (2015). In the main points developed by the authors, the applicability of the theories to the reading of the literary text was sought, providing an interartistic discourse that enhances new links between literature and photography.

KEYWORDS: literature. photography. literary dialogues.

Enfim, a imagem queima pela memória, ou seja, que ela queima ainda, ainda que só seja cinza: um jeito de expressar sua vocação essencial para a sobrevivência, para o apesar de tudo. Mas, para sabê-lo, para senti-lo, é preciso ousar, é preciso aproximar o rosto da cinza. E soprar suavemente para que a brasa, por debaixo, comece a emitir de novo seu calor, sua luz,

\footnotetext{
* Graduada em Letras- Habilitação em Língua Espanhola e Literaturas de Língua Espanhola pela Universidade Federal de Pelotas (2002). Especialista em Língua Espanhola (UCPel - 2004), Especialista em Educação (UFPel - 2009), e Especialista em Educação para a Diversidade (UFRGS 2014). Mestra em Letras - Área de Literatura Comparada (UFPel - 2017). Graduada em LetrasHabilitação em Língua Portuguesa e Literaturas de Língua Portuguesa pela ULBRA Canoas (2019). Doutoranda em Letras na UFPel, com ingresso em 2018/2. Áreas de interesse: escritas de si, autoficção, autobiografia, testemunho, literatura brasileira contemporânea, literatura e ditadura, literatura de autoria feminina.
} 
seu perigo. Como se, da imagem cinza, saísse uma voz: "Não vês que estou queimando?"

Didi-Huberman

A literatura e a fotografia são diferentes formas que a humanidade encontrou para expressar suas ideias e sentimentos, e também para registrar suas experiências. Apesar de apresentarem linguagens distintas, ambas possuem capacidade de propiciar reflexão ao sujeito, que se utiliza dessas e de outras formas de arte como possibilidades de reverberação da memória e da história. A obra literária selecionada para análise propicia um diálogo entre a literatura e a fotografia, por se tratar de um romance que enfatiza o tema da fotografia ao longo de seus desdobramentos, originando assim um encontro voltado para o diálogo interartístico entre literatura e fotografia em que a escrita literária é complementada pelo imaginário oriundo do universo fotográfico.

Em O corpo interminável, Cláudia Lage problematiza o tema dos desaparecidos políticos durante a ditadura militar brasileira. O protagonista é o personagem Daniel, filho de uma desaparecida política a quem ele somente conheceu através de relatos e histórias, e cuja imagem se faz presente em sua mente primordialmente através de fotografias. Ao buscar desvendar a história da mãe, que Daniel nunca conheceu, o personagem reconstrói também parte de sua vida, que estava perdida no passado que ele desconhecia, mas que, porém, aos poucos vai se revelando. Assim, o romance de Lage aborda também o tema da distância, da ausência, da falta, do silêncio, do vazio, de todos esses sentimentos que nos corroem e que parecem nunca terminar. Podemos aludir o desconhecimento de Daniel sobre parte de sua vida à amnésia que prevalece no Brasil no que se refere ao período da ditadura, constantemente marcado por silenciamentos e ocultamentos. Nesse sentido, a narrativa da autora atua como uma tentativa de resistência ao apagamento de parte de nossa história. Além de Daniel, também sua namorada, a personagem Melina, possui uma relação bastante peculiar com o tema da fotografia, já que a máquina fotográfica que ganhou ainda na infância originou uma série de episódios que a marcaram ao longo de sua vida.

Claudia Lage, a autora de O corpo interminável, é formada em teatro e iniciou sua carreira como roteirista, tendo passado a escrever posteriormente. Provavelmente 
por isso, o tema da imagem e da fotografia permeie grande parte da narrativa da autora. Já nas linhas iniciais, o protagonista Daniel se sente impactado por fotografias que vai encontrando ao longo de sua jornada: "Coloquei a foto na cabeceira. Poderia olhar a imagem novamente a qualquer momento. $E$ fiz isso durante a madrugada, muitas vezes. Por quê? Nada havia me escapado. Eu queria mais detalhes?" (LAGE, 2019, p. 21). A angústia sobre a incerteza de sua história e de seu passado acompanham o personagem ao longo de todo o romance:

Havia um avô e um menino, contei à Melina, esse menino cresceu imerso no silêncio do avô. Não sei se era alegre ou triste, era uma criança que não sabia da sua história, não sabia de nada. Tento lembrar, mas não consigo, não consigo me aproximar desse menino, olhar para dentro dele, pensar o que ele pensava, sentir o que sentia, medir até onde percebia as suas circunstâncias, o seu isolamento, o que Ihe faltava. Por muito tempo, não pensei na minha infância, era como se tivesse passado por ela de olhos fechados. A escola, os amigos, os livros, os cadernos, a professora. A professora que um dia chamou meu avô para uma conversa. Com a minha redação na mão, ela me olhava, foi você mesmo que escreveu? Sim, fui eu, mas ela não acreditava. Era preciso a confirmação do meu avô. Um menino não escreveria sobre a morte da própria mãe daquela maneira. $\mathrm{O}$ avô não apareceu, a professora, inconformada, não sabia o que fazer comigo. Um menino que imaginava a morte da mãe de diferentes formas. Que colocava sangue e violência nessas mortes. A diretora veio em socorro, a sua mãe pode aparecer, meu filho, a qualquer momento, o seu avô me disse, ela foi viajar, mas volta. Eu não consigo lembrar o que respondi, se acreditava ou se duvidava dessa volta. Já tinha escutado muitas vezes a palavra desaparecimento, já entendia o seu significado, alguém estar ali e de repente não estar mais. (LAGE, 2019, p. 25)

Assim, percebemos que o menino Daniel, desde a infância, herdou o silêncio que acabou o acompanhando por toda sua vida. Em outra passagem, percebe-se a importância das fotografias na vida de Daniel, já que a mãe o deixou aos cuidados do avô logo que o menino nasceu, partindo para a vida clandestina de uma refugiada política do período ditatorial brasileiro. Crescendo em meio ao desconhecido, sem saber sobre o paradeiro da mãe e sequer se ela estaria viva ou morta, e ainda cercado por todos os mistérios e não ditos que rondam o período da ditadura, as fotografias operaram na vida de Daniel como uma forma de ligação com parte de sua vida desconhecida, seja porque ele não teve contato com a mãe, seja também pela incompreensão de parte de sua origem e história: 
O rosto do pai não está em nenhuma fotografia. O rosto da mãe está numa única foto dada pelo avô com a sentença, foi o que restou. $A$ expressão congelada no tempo mostra uma jovem bela e sorridente, apenas isso, garoto. A foto lhe dizia pouco, mas era tudo o que tinha. O avô não falava, apesar das perguntas. O sorriso foi só para a foto, ou ela sorria sempre assim? Que lugar bonito é esse? Quem estava atrás da câmera? Foi o senhor quem tirou a foto? Foi o meu pai? (...) Diante do prato vazio, o menino insistia. D. Jandira não tinha jeito de que ia falar, mas disse: não foi o seu avô quem tirou a foto. E só disse porque o senhor já tinha saído da cozinha, assistia na sala à TV. O menino ainda segurava a colher quando ouviu. Não sabemos quem estava atrás da câmera. Pode ter sido o seu pai. Mas não sabemos. D. Jandira o serviu de novo. O lugar bonito deve ser longe. Ou não. Pode ser qualquer lugar. $O$ prato cheio até a borda, quase transbordando. Ela não sorriu só para a foto não. A sua mãe sorria sempre assim. (LAGE, 2019, p. 37)

Apesar de a ditadura brasileira ser marcada por silenciamentos e ocultamentos, o tema vem ocupando espaço significativo em produções literárias de autores e autoras que buscam debater a herança que a ditadura nos deixou. Produções como A chave de casa (2012), de Tatiana Salem Levy, ou K: relato de uma busca (2011), de Bernardo Kucinski, para citarmos apenas alguns exemplos, problematizam o período ditatorial brasileiro na literatura brasileira contemporânea. No referido romance de Kucinski, o autor aborda o tema dos desaparecidos políticos da ditadura militar brasileira a partir da experiência que vivenciou com sua própria irmã, que sumiu na década de 70 sem deixar rastros, tornando-se mais um dos muitos casos de desaparecidos políticos no Brasil. Já no romance de Levy, a narradora que nasceu em contexto de exílio, filha de pais militantes políticos, relata as consequências do período ditatorial na sua vida e na de sua família. Também em Antes do passado: o silêncio que vem do Araguaia (2012), a autora Liniane Brum aborda a questão do desaparecimento de militantes políticos durante o período da ditadura brasileira, partindo da história de seu tio Cilom Brum, membro da Guerrilha do Araguaia que foi sequestrado, e cujo corpo nunca foi encontrado. Nesse sentido, também a produção literária de Claúdia Lage contribui para a problematização tão necessária do tema da ditadura na contemporaneidade, já que grande parte dos brasileiros desconhece parte da própria história.

No romance da autora, um momento aparentemente simples e insignificante torna-se perpétuo devido ao registro fotográfico, passando a fazer parte da história. Uma história inacabada, já que muitas informações permanecem indisponíveis: quem fotografou a mãe de Daniel?, onde a foto foi tirada?, a mãe do menino era sempre 
alegre e sorridente, ou forçou uma imagem falsa no momento da foto? Apesar de todos os mistérios que rondam a história da mãe de Daniel, uma desaparecida política do período da ditadura, parte do silêncio que circunda sua vida foi suspenso no instante em que se produziu seu registro fotográfico.

Em Pequena história da fotografia, Walter Benjamin defende que o surgimento da fotografia introduziu algo de estranho e novo:

na vendedora de peixes de New Haven, olhando o chão com um recato tão displicente e tão sedutor, preserva-se algo que não se reduz ao gênio artístico do fotógrafo Hill, algo que não pode ser silenciado, que reclama com insistência o nome daquela que viveu ali, que também na foto é real, e que não quer extinguir-se na "arte". (BENJAMIN, 1996, p. 93).

Com isso, Benjamin aponta a fotografia enquanto possibilidade de preservação e de valorização daquilo que é fotografado, em que as "centelhas do acaso" vão se desnudando ao fotógrafo. Benjamin defende que somente a fotografia possibilita a revelação do inconsciente ótico, devido aos seus recursos auxiliares que possibilitam um detalhamento que é, ao menos teoricamente, imperceptível ao consciente daquele que observa:

a técnica mais exata pode dar às suas criações um valor mágico que um quadro nunca mais terá para nós. Apesar de toda a perícia do fotógrafo e de tudo o que existe de planejado em seu comportamento, o observador sente a necessidade irresistível de procurar nessa imagem a pequena centelha do acaso, do aqui e agora, com a qual a realidade chamuscou a imagem, de procurar o lugar imperceptível em que o futuro se aninha ainda hoje em minutos únicos, há muito extintos, e com tanta eloquência que podemos descobri-lo, olhando para trás. A natureza que fala à câmara não é a mesma que fala ao olhar; é outra, especialmente porque substitui a um espaço trabalhado conscientemente pelo homem, um espaço que ele percorre inconscientemente. (BENJAMIN, 1996, p. 94)

A fotografia é capaz de tornar marcante momentos aparentemente insignificantes, como ocorre com a personagem Melina de O corpo interminável, ao fotografar seu próprio pai:

Um dia, eu estava na varanda, com a minha máquina, quando o vi voltando para casa. Nossa casa tinha dois andares, e eu estava no alto. Tirei as fotos sem pensar, quase por hábito de fotografar o que me impressionava. Só depois, vi: fotos do meu pai subindo a rua. 
Sentado na calçada antes de entrar pelo portão. O rosto mergulhado nas mãos. A minha reação foram arrepios, mas não sabia que era tão grave. Só quando a minha mãe viu as fotos que eu soube. As fotos dele em movimento não eram novidade, mas aquela, meu pai sentado no meio-fio, as costas curvadas, as mãos espremendo o rosto, a deixou perplexa. Só quando vi o seu espanto reconheci o meu. De repente, éramos cúmplices. Estávamos muito impressionadas. O meu pai fora pego em flagrante. O seu olhar me dizia isso, ela não tinha sido a minha única vítima. Essa sua máquina é terrível, balbuciou, acendendo um cigarro, espalhando a fumaça pelo ar, papai tem muitas preocupações, não vamos aborrecê-lo com bobagens, e guardou as fotos numa pasta, a pasta numa gaveta, a gaveta num armário, 0 armário à chave. (LAGE, 2019, p. 64)

Ao fotografar displicentemente o pai, a família pode perceber situações e sentimentos que não estavam visíveis anteriormente ao registro fotográfico pois a afirmação de Benjamin (1996, p.104) de que "cada um de nós pode observar que uma imagem, uma escultura e principalmente um edifício são mais facilmente visíveis na fotografia que na realidade" se aplica também para os registros fotográficos de mulheres e homens, que tem suas expressões congeladas pelo clique do instante. Assim, Benjamin aponta para o uso da máquina fotográfica como um recorte do real, que através de seus recursos auxiliares possibilita a experiência de um inconsciente ótico, já que a fotografia oportuniza a consciência de determinadas particularidades de representação que não eram perceptíveis de forma natural ou direta:

Percebemos, em geral, o movimento de um homem que caminha, ainda que em grandes traços, mas nada percebemos de sua atitude na exata fração de segundo em que ele dá um passo. A fotografia nos mostra essa atitude, através dos seus recursos auxiliares: câmara lenta, ampliação. Só a fotografia revela esse inconsciente ótico, como só a psicanálise revela o inconsciente pulsional. (BENJAMIN, 1996, p. 94)

Já Roland Barthes, em livro intitulado A Câmara clara, discorre sobre conceitos acerca do tema da fotografia, na maior parte das vezes acompanhados de uma série de exemplificações, em que o autor busca "formular, a partir de alguns movimentos pessoais, o universal sem o qual não haveria Fotografia." (BARTHES, 1979, p. 19). A fotografia sempre instigou a curiosidade do autor, que a considerava peculiar quando comparada às demais formas de imagem: "Essa questão se fazia insistente. Em relação à Fotografia, eu era tomado de um desejo "ontológico": eu queria saber a qualquer preço o que ela era 'em si', por que traço essencial ela se distinguia da 
comunidade das imagens." (BARTHES, 1979, p. 12). Para o autor, a fotografia se esquiva a classificações, tornando-se assim inclassificável. Barthes entende que a fotografia reproduz o que só acontece uma vez: "ela repete mecanicamente o que nunca mais poderá repetir-se existencialmente." (BARTHES, 1979, p. 13).

Para Barthes, a natureza da fotografia remete a algo de tautológico, já que sempre traz consigo algo de seu referente: "a Fotografia pertence a essa classe de objetos folhados cujas duas folhas não podem ser separadas sem destruí-los." (BARTHES, 1979, p. 15). O autor entende que a fotografia pode ser objeto de três diferentes práticas, e com isso introduz os conceitos de Operator, Spectrum e Spectator, em que o Operator seria o fotógrafo, o Spectator seria o consumidor da foto, e o Spectrum seria o fotografado (o referente), o que o autor relaciona com a ideia de espetáculo, e também de retorno do morto. Outros conceitos bastante relevantes na teoria desenvolvida por Barthes sobre o tema da fotografia são os de Studium e Punctum. O autor identifica cinco funções a partir do conceito de Studium, e para ele a ideia de Studium está relacionada ao gosto pela fotografia, e também ao tema da cultura:

É pelo studium que me interesso por muitas fotografias, quer as receba como testemunhos políticos, quer as aprecie como bons quadros históricos: pois é culturalmente (essa conotação está presente no studium) que participo das figuras, das caras, dos gestos, dos cenários, das ações. (BARTHES, 1979, p. 45-46).

Esse aspecto cultural dado à fotografia acabou por inseri-la no universo social, pessoal e familiar, já que o hábito de registrar o dia a dia através do exercício de fotografar foi se tornando, com o passar dos anos, cada vez mais corriqueiro. No entanto, o gosto pela fotografia se manifesta com diferentes intensidades entre uma e outra pessoa. No romance analisado, a personagem Melina, namorada do protagonista Daniel, rememora a aquisição de sua primeira máquina fotográfica, que despertou, ainda na infância, sua paixão pelo ato de fotografar:

Um dia, ainda menina, ganhei de presente de aniversário uma máquina fotográfica, Melina continuou. Lembro da surpresa ao desfazer o embrulho. Não é brinquedo, é de verdade, ouvi a frase. Se fosse de criança, seria uma máquina de mentira, uma máquina faz de conta. Iria apenas brincar de fotógrafa, uma grande farsa. Mas algo incrível havia acontecido. Naquela manhã mesmo constatara ao acordar dois inconfundíveis montinhos sob a camisola. Em seguida, 
como num passe de mágica, ganhava um presente de adulto. É portátil, ela continuou, para você levar aonde quiser. Para onde eu quisesse, era uma promessa de liberdade que eu não esperava ter tão cedo.

Nos primeiros dias, vivi em euforia. A casa toda se tornou paisagem. Gostava de tirar fotos dos objetos mais rotineiros, como a minha caneca florida, às vezes cheia de leite, outras vezes com o restinho do líquido nas bordas e no fundo. Não reparava que nunca tirava da caneca limpa. Foi ela que reparou, você não tira foto das coisas antes de usadas e nem depois de lavadas. Por quê? Acho mais bonito, respondi. (LAGE, 2019, p. 61)

A personagem Melina, aficionada por fotografia, desde o início de sua prática demonstrou interesse pelo registro de momentos rotineiros, o que poderia ser considerado como um exemplo de alusão ao conceito de studium proposto por Barthes. No entanto, o autor entende que um outro elemento coabita as fotografias, juntamente com o studium, porém com características diferentes: seria o punctum, que se origina da ideia de uma ferida, marca ou picada. Então, para Barthes,

A esse segundo elemento que vem contrariar o studium chamarei então punctum; pois punctum é também picada, pequeno buraco, pequena mancha, pequeno corte - e também lance de dados. $O$ punctum de uma foto é esse acaso que, nela, me punge (mas também me mortifica, me fere). (BARTHES, 1979, p. 46, grifos do autor).

O autor entende o studium enquanto um campo bastante vasto, diferentemente do punctum, que daria uma maior peculiaridade à fotografia. A partir dessa distinção, o autor introduz a ideia de fotografia unária, que seria a imagem que não causa choque, que não causa distúrbio, não fere, ou seja, não tem punctum, não é uma foto digna de rememoração, como no caso das fotos da caneca de leite que eram tiradas pela personagem Melina. Segundo o autor:

A Fotografia é unária quando transforma enfaticamente a 'realidade, sem duplicá-la, sem fazê-la vacilar (a ênfase é uma força de coesão): nenhum duelo, nenhum indireto, nenhum distúrbio. A Fotografia unária tem tudo para ser banal, na medida em que a 'unidade' da composição é a primeira regrada retórica vulgar (e especialmente escolar): ' $\mathrm{O}$ tema, diz um conselho aos fotógrafos amadores, deve ser simples, livre de acessórios inúteis; isso tem um nome: a busca da unidade. (BARTHES, 1979, p. 66). 
Para o autor, a fotografia não é uma questão de arte ou de uso, mas sim de referente, por mostrar aquilo que já existiu, ou seja, para Barthes a fotografia estará sempre relacionada com a ideia da morte: o tempo é o punctum da fotografia.

A personagem Melina rememora os primeiros registros fotográficos, em que clicava os pais em momentos de descontração e improviso, ocasionando em fotos que, nas palavras de Barthes, estariam coabitadas pelo studium e também pelo punctum, já que ocasionam um desconforto na mãe, que é a personagem fotografada:

Mas o suplício começou realmente quando os primeiros filmes foram revelados. Ela fumou dois cigarros inteiros olhando as fotos, enquanto eu aguardava o seu veredicto sentada na cadeira da cozinha. (...) Ela separou as fotos em dois bolos e me estendeu um, com ar de interrogação. Eram fotografias que eu tirara dos meus pais. O meu pai saindo do quarto, a minha mãe penteando os cabelos, os dois na mesa do café da manhã ou do almoço. Ela estava surpresa, não sabia que eu os fotografava, imaginava que eu mirava algum objeto ou planta qualquer quando passava com a minha câmera. Estava aborrecida, em todas as fotografias ela aparecia com semblante distante e triste. E ela não era triste, ria, era feliz, mas que impertinência, que menina cruel eu tinha sido, ela não era triste. (LAGE, 2019, p. 62)

Já outra estudiosa do tema da fotografia, a autora Susan Sontag, em livro intitulado Sobre a fotografia, diferencia a prática da fotografia das demais formas de imagem, as quais ela denomina de "mais artesanais":

Essa insaciabilidade do olho que fotografa altera as condições do confinamento na caverna: o nosso mundo. Ao nos ensinar um novo código visual, as fotos modificam e ampliam nossas ideias sobre o que vale a pena olhar e sobre o que temos o direito de observar. (SONTAG, 2004, p. 13).

A autora defende que colecionar fotos é colecionar o mundo, e que fotografar é apropriar-se da coisa fotografada, sendo que as fotos operam ainda enquanto uma forma de testemunho: "Fotos fornecem um testemunho. Algo de que ouvimos falar mas de que duvidamos parece comprovado quando nos mostram uma foto" (SONTAG, 2004, p. 16), destacando ainda que o uso popular mais antigo da fotografia é o de comemorar as conquistas dos indivíduos, sendo que cada família constrói uma crônica visual de si mesma através das fotos. Essa espécie de crônica familiar a que Sontag faz alusão foi praticamente uma ausência na infância da personagem Melina, que se sentia incomodada com o desinteresse dos pais pela prática de fotografar, 
sendo que a jovem, ao contrário dos pais, buscava incessantemente o registro do dia a dia através das fotos:

Os meus pais só tiravam fotos posadas em cerimônias e festas e celebrações. Eu gostava de tirar da caneca suja de leite depois do café da manhã, do bigode branco sobre meus lábios, do olhar distante que ela tinha quando se sentava à nossa mesa, como se esperasse sempre se sentar em outro lugar, e então diariamente era desapontada e surpreendida. Numa das fotos, meu pai estava em meio ao movimento de se levantar da cadeira, depois de ter tomado rapidamente um gole de café, dado uma mordida apressada na torrada com manteiga. Ao lado, ela não esboçou nenhuma reação. $O$ meu pai se levantava, se afastava, e a minha mãe permanecia com o olhar ausente, a xícara nas mãos. Não reagira à presença nem à ausência. Depois, ela viu a foto, com profundo desgosto. Para que fotografar as pessoas em meio à uma ação inacabada, um olhar esvaído num segundo de reflexão, um gesto insignificante? (LAGE, 2019, p. 63)

Sobre a prática da fotografia, Sontag compara a câmera fotográfica ao automóvel, ambos vendidos como arma predatória, e de uso viciante: "No fim, as pessoas talvez aprendam a encenar suas agressões mais com câmeras do que com armas, porém o preço disso será um mundo ainda mais afogado em imagens." (SONTAG, 2004, p. 25). Para a autora, a prática da fotografia é fomentada por uma época nostálgica, já que incita o desejo e funciona como uma forma de pseudopresença, defendendo ainda que as fotos tendem a ser mais memoráveis do que as imagens em movimento, já que são uma nítida fatia de tempo, e não um fluxo. Para Sontag (2004, p. 34-35):

A necessidade de confirmar a realidade e de realçar a experiência por meio de fotos é um consumismo estético em que todos, hoje, estão viciados. As sociedades industriais transformam seus cidadãos em dependentes de imagens; é a mais irresistível forma de poluição mental. [...] Hoje, tudo existe para terminar numa foto.

Esse consumismo estético propiciado pelo ato de fotografar a que alude Sontag ocasiona em uma sociedade que se utiliza da imagem e da fotografia como formas de referência do que já foi vivido. Assim, muitas vezes a imagem opera como substituta do que um dia existiu, mas que no momento não se faz presente. A partir da trama do personagem Daniel, filho de uma desaparecida política que ele nunca conheceu, 
Cláudia Lage problematiza as consequências dos silenciamentos e dos apagamentos no tempo presente:

O armário também tinha sido da minha mãe, como a cama, como as janelas de madeira, que graças ao avô nunca aderiram ao alumínio. A madeira da parte de dentro do armário e da janela tinha raspas, como grandes arranhões. Um dia, percebi numa das fissuras um pedacinho de papel colorido. Era o resto de uma foto, de um adesivo, de uma imagem qualquer. Eu nunca tinha reparado, a madeira tinha sido raspada para tirar as imagens. Fotos, adesivos, que deviam ser da minha mãe, que ela devia gostar muito, que deve ter colocado dentro do armário para ver sempre que abria a porta, ou na janela, para ficar olhando até dormir. Podia ser foto dela, do meu pai, de amigos, de um ator ou da sua banda preferida. Eu nunca vou saber. Se a madeira não tivesse sido raspada, eu poderia ter visto outra foto da minha mãe, ela estaria sorrindo também, como disse D. Jandira? - ou teria conhecido o rosto do meu pai. Talvez eu seja parecido com ele, talvez eu estranhasse a semelhança, como se visse, num espelho distorcido, os meus traços em outro rosto. Ou não, os traços dele é que estariam em meu rosto, porque são sempre os filhos que repetem os pais. Se a madeira não tivesse sido raspada, eu poderia ter conhecido o ator que ela olhava até dormir, teria visto um filme com ele, assistido às cenas pensando, os seus olhos tinham visto as mesmas imagens que os meus. Ou não, os meus é que teriam visto as mesmas imagens que os olhos da minha mãe, por que são sempre os filhos que veem depois. $\mathrm{E}$ a banda, se a madeira não tivesse sido raspada, eu poderia ter hoje todos os álbuns da sua banda preferida. De repente, até tenho e não sei. De repente, escuto as mesmas músicas que ela escutava. Pode ser. Eu poderia ouvir uma música e dizer, minha mãe gostava dessa música. E poderia ficar ouvindo a música de que ela gostava. Mas a madeira foi raspada, e eu não posso. A madeira foi raspada, e eu não sei. (LAGE, 2019, p. 39)

Assim, Daniel tenta aprender a conviver com a dor de duas ausências: a ausência da mãe, e de parte de sua história, uma história que não é somente dele, mas de toda uma geração que foi impactada por sequestros, torturas, prisões, desaparecimentos, por atrocidades das mais diversas que ocasionaram em uma sociedade traumatizada e emudecida, que parece preferir não narrar para não lembrar. No entanto, mesmo a "madeira raspada" da casa de Daniel remete o personagem à rememoração e à reflexão sobre um tempo que não passou, sobre um episódio da história do Brasil que ainda deixa sequelas no tempo presente.

Outro teórico da fotografia, o autor André Bazin, em livro intitulado Ontologia da imagem fotográfica, problematiza a relação entre o objeto e sua representação, partindo de uma perspectiva ontológica da fotografia, como o fez Barthes. O autor, que pensa o cinema partindo da fotografia, e a fotografia partindo das artes visuais, 
traça um paralelo entre a "representação" que a fotografia faz de um objeto, e a "representação" que um corpo embalsamado faz de um corpo "vivo", sob o que ele denomina de complexo da múmia. Diferentemente de Benjamin, que entende a fotografia como uma revolução, uma inovação, Bazin defende que a fotografia seria uma forma de luta contra o tempo e contra a morte, e estaria no lugar do objeto, da coisa representada, assim como a múmia estaria no lugar do corpo vivo, em uma busca de um espaço na história e na memória, ou seja, na sua essência a fotografia remete a uma prática de representação que é pensada desde a antiguidade, como uma forma de "salvar o ser pela aparência" (BAZIN, 1991, p. 19), em uma tentativa de luta contra a morte, que contribui com a defesa do homem contra o tempo.

No romance estudado, a dor e a saudade originadas pela ausência da mãe do protagonista são problematizadas também partindo do tema da fotografia. Ao tentar descobrir a história da mãe, o personagem sente imensa necessidade de visualizá-la em fotos, como se a fotografia pudesse substituir a presença física da mãe. Assim, partindo de Bazin, podemos entender que o personagem Daniel busca nas fotos da mãe (que sequer existem) uma forma de lutar contra a dor de uma ausência. Bazin argumenta ainda que a fotografia tomou para si a obrigatoriedade da semelhança, o que antes de sua invenção era uma exclusividade das artes plásticas. Ao comparar a fotografia com as artes plásticas, o autor defende que "pela primeira vez, entre o objeto inicial e a sua representação nada se interpõe, a não ser um outro objeto. Pela primeira vez, uma imagem do mundo exterior se forma, automaticamente, sem a intervenção criadora do homem, segundo um rigoroso determinismo." (BAZIN, 1991, p. 22). Nessa passagem, podemos perceber uma afinidade entre o pensamento de Bazin e o de Benjamin, já que ambos entendem que entre o que é fotografado e a fotografia não há a intervenção do fotógrafo. Assim, o autor entende a fotografia como uma técnica superior quando comparada às demais artes plásticas, tais como a pintura. Para Bazin, o surgimento da fotografia propiciou uma autonomia estética às artes plásticas, que se libertaram do compromisso com o realismo, passando-o à fotografia, que segundo o autor apresentam virtualidades estéticas que residem na "revelação do real" (BAZIN,1991, p. 24).

Já o fotógrafo Henri Cartier-Bresson, no texto $O$ instante decisivo, relata sua experiência particular sobre o ato de fotografar e, assim como Benjamin, também entende a câmera fotográfica como um prolongamento do olho humano. O fotógrafo alude ao instante decisivo como um momento essencial, que ao ser registrado pela 
fotografia, se diferencia de todos os demais, por ser uma oportunidade única, especial, para se contar uma história. Assim, Cartier-Bresson entende a fotografia como uma forma de linguagem, de narração, e alude à ideia de reportagem fotográfica para designar "uma operação progressiva da cabeça, do olho e do coração para exprimir um problema, fixar um evento ou impressões" (CARTIER-BRESSON, 2015, p. 17). No ensaio, o fotógrafo destaca outros aspectos importantes da fotografia, tais como 0 tema, a composição, a técnica e também os clientes. Para Cartier-Bresson, na imagem fotográfica o conteúdo não pode separar-se da forma, e a fotografia pode ser entendida como "o reconhecimento simultâneo, numa fração de segundo, por um lado, da significação de um fato, e por outro, de uma organização rigorosa das formas percebidas visualmente que exprimem este fato" (CARTIER-BRESSON, 2015, p. 29). Dessa forma, o fotógrafo entende que as fotografias, assim como as palavras, também narram, diferentemente do que aparentemente pensa o narrador de $O$ corpo interminável:

A imagem. Eu li em algum lugar que uma foto, por si, não revela nenhum significado, apenas uma aparência. Todos os esforços de interpretação não passarão de esforços, e a imagem nunca passará de uma imagem. Para ultrapassar a aparência é preciso narrar e a imagem não narra, é preciso existir testemunhos dos acontecimentos e não temos, nossa mente se detém no formato de uma foto assim como nossos olhos, estamos soltos no tempo e presos na aparência. Não podemos narrar. (LAGE, 2019, p. 105)

O crítico de cinema e fotografia Arlindo Machado, autor do livro $A$ ilusão especular, questiona as relações entre a fotografia e a realidade, propondo uma crítica à "figuração automática" atribuída à fotografia, que seria uma suposta capacidade que a fotografia tem de reproduzir a realidade. A ilusão especular seria uma alusão à relação entre fotografia e realidade: por convenções historicamente definidas e aceitas como verdades praticamente incontestáveis. Para Machado, a fotografia não reproduz necessariamente a realidade:

Os "realistas" sempre pressupõem tacitamente que a coisa mais evidente, a mais notória, aquela que menos exige o exame de seu sentido, é justamente a "realidade": mas de que realidade falam eles? $\mathrm{Na}$ verdade, eles endossam o equívoco imposto pela ideologia dominante, ao considerar uma certa representação da realidade como a realidade mesma e um determinado modo de apropriação do mundo como o único autêntico. (MACHADO, 1984, p. 40) 
Assim, para Machado, a fotografia opera mais como um simulacro da realidade, como também aponta Susan Sontag. O autor entende a fotografia como algo não transparente, uma reprodução da cultura que necessita ser interpretada:

Ora, se é verdade que as câmeras "dialogam" com informações luminosas que derivam do mundo visível, também é verdade que há nelas uma força formadora muito mais que reprodutora. As câmeras são aparelhos que constroem as suas próprias configurações simbólicas, de outra forma bem diferenciada dos objetos e seres que povoam o mundo; mais exatamente, elas fabricam "simulacros", figuras autônomas que significam as coisas mais que as reproduzem. (MACHADO, 1984, p. 11)

O romance $O$ corpo interminável propicia reflexões sobre as relações entre a literatura e a fotografia: por um lado, a partir da história de Daniel, o filho da desaparecida política do período da ditadura, podemos refletir sobre a importância da fotografia enquanto um espaço de manutenção da memória e da história, e também considerar as peculiaridades da fotografia enquanto forma de representação ou não da realidade. Levando em consideração os ainda incipientes estudos sobre as relações entre a literatura e a fotografia, foram selecionados, para o estudo do texto literário, teóricos e teóricas que se dedicam ao estudo da fotografia, em uma espécie de retomada dos pontos principais desenvolvidos por cada autor, bem como de sua possível aplicabilidade para a leitura de um texto literário que se desenvolve com o auxílio de diversas alusões ao tema da imagem fotográfica.

Iniciando por Walter Benjamin, se apresentou o conceito de inconsciente ótico da fotografia, que explica a observação de detalhes ou particularidades que possivelmente não seriam consideradas em uma situação de ausência de imagens fotográficas. Já a partir de Barthes, foi dado destaque aos conceitos de studium, punctum e foto unária, partindo do enredo protagonizado pela personagem Melina, para quem o exercício de fotografar consistia em algo bastante importante e peculiar, porém muitas das vezes voltado para o registro do banal e do comum. Mesmo assim, a personagem produziu imagens fotográficas que marcaram a família, em especial, a mãe, fotos estas portadoras, nas palavras de Barthes, de um punctum que fere e mortifica. Ao longo do romance de Claúdia Lage, podemos perceber diversas passagens em que a fotografia fere, marca, mortifica os personagens Daniel e Melina, e também aqueles que com eles convivem. Já apoiado em Bazin foi apresentado o 
conceito de "complexo da múmia", em que o autor traça um paralelo entre a representação que a fotografia faz de um objeto, e a representação que um corpo embalsamado faz de um corpo vivo. Baseado em Henri Cartier-Bresson foi apresentado o conceito de instante decisivo, que é entendido pelo fotógrafo enquanto um momento essencial, que ao ser registrado pela fotografia, se diferencia de todos os demais, por ser uma oportunidade única, especial, para se contar uma história. Sendo assim, para Cartier-Bresson a fotografia é uma forma de narrar, assim como para Susan Sontag a fotografia opera como uma forma de testemunhar. Por fim, mas não menos importante, foi apresentada a ideia de ilusão especular proposta por Arlindo Machado. O autor, ao problematizar as relações entre fotografia e realidade, defende que a representação da realidade imposta pela fotografia seria um equívoco, uma ilusão propiciada por convenções históricas e verdades incontestáveis.

Finalizando, o presente artigo buscou apresentar um apanhado sobre as principais ideias que versam sobre o tema da fotografia partindo de autores que se aprofundaram em seu estudo, para a seguir buscar algumas exemplificações destes conceitos em um texto literário que se desenvolve também a partir de diversas alusões ao tema da fotografia, possibilitando assim um diálogo entre os diferentes discursos: o literário e o fotográfico. Entendendo que tanto a palavra quanto a fotografia são imagens que carregam significados, e assim propiciam a imaginação, conclui-se que o diálogo entre a literatura e a fotografia possibilita a potencialização da expressão artística, tão necessária para a manutenção da história e da memória, bem como para o surgimento de novos elos que renovam e enriquecem o fazer literário, já que tanto a palavra quanto a fotografia são imagens que ferem, que queimam, e que também tornam-se uma forma de sobrevivência e resistência para aqueles que delas se utilizam.

\section{Referências}

BARTHES, Roland. A câmara clara: nota sobre a fotografia. Tradução de Júlio Castañon Guimarães. Rio de Janeiro: Nova fronteira, 1984.

BAZIN, André. Ontologia da imagem fotográfica. O cinema: ensaios. Tradução de Eloisa de Araújo Ribeiro. São Paulo: Brasiliense, 1991. 
BENJAMIN, Walter. Pequena história da fotografia. In: Magia e técnica, arte e política: ensaios sobre literatura e história da cultura. Obras Escolhidas Vol 1. Tradução de Sergio Paulo Rouanet. São Paulo: Brasiliense, 1996.

CARTIER-BRESSON, Henri. O momento decisivo. O imaginário segundo a natureza. Tradução de Renato Aguiar. São Paulo: Gustavo Gili, 2015.

LAGE, Cláudia. O corpo interminável. Rio de Janeiro: Record, 2019.

MACHADO, Arlindo. A ilusão especular: uma teoria da fotografia. São Paulo: Gustavo Gili, 2015.

SONTAG, Susan. Sobre fotografia. Tradução de Rubens Figueiredo. São Paulo: Companhia das Letras, 2004. 